\title{
Sentimentos partidários e igualdade de gênero no Brasil
}

\author{
Partisans feelings and gender equality in Brazil
}

\author{
Audrey Karoline Marques Dias \\ Mestranda do Programa de Pós-graduação \\ em Ciências Sociais \\ Universidade Estadual de Maringá \\ e-mail: amarquesdias@hotmail.com

\section{Ednaldo Aparecido Ribeiro} \\ Professor Adjunto do Programa de Pós-graduação \\ em Ciências Sociais \\ Universidade Estadual de Maringá \\ e-mail: ednaldorip@uol.com.br
}

Recebido: 03/04/2013

Aceito: 16/07/2013
RESUmo No ano de 2010 a população brasileira elegeu uma mulher para o cargo de presidente do Brasil. Apesar desse fato, dados apresentados por diferentes organizações internacionais denunciam um quadro de sub-representação feminina. Algumas tentativas de explicação têm sido propostas, mas parece existir um consenso sobre a natureza multicausal do fenômeno, que envolveria fatores estruturais, institucionais e culturais. O presente artigo pretende analisar uma dimensão do problema que se situa na interface entre as instituições e a cultura política dos cidadãos, focalizando os sentimentos partilhados pelos indivíduos em relação aos partidos políticos mais relevantes no cenário nacional e a sua associação com disposições favoráveis ao voto em mulheres. Mais especificamente, analisa as relações entre os sentimentos relativos aos partidos PT e PSDB, e atitudes dos brasileiros a respeito do papel da mulher na política, usando para tanto os dados coletados pelo Estudo Eleitoral Brasileiro (ESEB), na terceira onda de pesquisa pós-eleitoral, efetivada em 2010.

PalaVRas-Chave Sentimentos partidários; Gênero no Brasil; Comportamento político.

ABSTRACT In 2010 the Brazilian population elected a woman to the post of president of Brazil. Despite this fact, data presented by different international organizations denounce a picture of female under-representation. Some tentative explanations have been proposed, but there seems to be a consensus on the nature of the multi-causal phenomenon, which involve structural factors, institutional and cultural. This article analyzes one dimension of the problem which is located at the interface between institutions and the political culture of citizens, focusing on the feelings shared by individuals in relation to political parties more relevant on the national scene and the association with provisions favorable to vote in women. More specifically, analyzes the relationship between feelings relative to the PT and PSDB party, and attitudes of Brazilians, about the role of women in politics, using for this purpose the data collected by the Estudo Eleitoral Brasileiro (ESEB), the third wave of post-election survey, carried out in 2010.

KEYwORDS Partisans feelings; Gender in Brazil; Political behavior. 


\section{Introdução}

A sub-representação política das mulheres pode ser identificada como um dos elementos deficitários das democracias ocidentais contemporâneas (Norris, 2011), chamando a atenção tanto de pesquisadores acadêmicos como de atores políticos coletivos governamentais e independentes. Dados produzidos por diferentes organismos internacionais, como o Inter-Parliamentary Union (IPU), o Fórum Econômico Mundial (FEM) e a Comissão Econômica para a América Latina (CEPAL), indicam um quadro negativo em termos de igualdade política entre homens e mulheres no cenário global, ainda que mudanças importantes venham ocorrendo nas últimas décadas, em especial nas nações economicamente desenvolvidas.

Utilizando dados do projeto World Values Survey (WVS) em pesquisa comparada envolvendo mais de 70 países, Ronald Inglehart e Pippa Norris (2003: 34) identificaram forte ligação entre essa persistente sub-representação feminina e baixos níveis de desenvolvimento econômico. Sociedades com reconhecidos níveis de desenvolvimento, tais como Finlândia, Suécia e Alemanha, aparecem nas primeiras posições no ranking dos países que apresentam maior igualdade de gênero. De uma forma geral, sociedades agrárias apresentam menor equidade entre gêneros que nações industriais e essas últimas, por sua vez, são mais desiguais que nações consideradas pós-industriais.

Apesar desses achados, os autores alertam para a insuficiência da explicação econômica, uma vez que os mesmos dados analisados revelaram que países como Moçambique, África do Sul e Venezuela possuem índices mais altos de representação feminina em cargos eletivos do que os Estados Unidos, França e Japão. Os três primeiros se encontram em $9^{\circ}, 10^{\circ}$ e $11^{\circ}$ lugares, respectivamente, enquanto as três últimas nações (com altos níveis de desenvolvimento econômico) estão na $15^{\circ}, 59^{\circ}$ e $94^{\circ}$ posição. Este cenário ambíguo, no qual indicadores distintos se comportam de forma muito diferente nessas realidades nacionais, corrobora a ideia de que o fenômeno da sub-representação feminina é multicausal, envolvendo sim barreiras estruturais, mas também institucionais e culturais.

No Brasil, informações do IPU indicam que as mulheres ocupavam no final de 2012 apenas 8,6\% das cadeiras na Câmara dos Deputados e $16 \%$ no Senado. Esses percentuais colocam o país no $123^{\circ}$ lugar considerando um total de 190 países de diferentes regiões do globo. A sistematização dos dados do FEM de 2012 para 135 países revela que o Brasil ocupa o $62^{\circ}$ lugar no ranking geral de avanços na promoção da igualdade de gênero ${ }^{1}$, mas quando consideramos apenas o item relativo ao "empoderamento" político feminino caímos para o $72^{\circ}$ lugar (Hausmann, Tyson e Zahidi, 2012) ${ }^{2}$. Por fim, os dados da CEPAL para 15 países da região mostram que, no Brasil, existem $21,8 \%$ de mulheres nos cargos de primeiro escalão da presidência no atual mandato de Dilma Rousseff. Apesar de reduzido, esse percentual representa evolução nesse indicador na comparação com os dois governos anteriores de Lula da Silva, nos quais encontramos apenas 10,7 e 14,8 pontos, respectivamente.

Esse quadro geral tem alimentado o debate sobre as potencialidades e os limites de medidas institucionais, como a política de cotas instituída em nosso país em 1996, para promover a inclusão feminina nas instâncias de decisão. Araújo (2001), por exemplo, demonstra que após essa medida houve aumento considerável no número de candidatas, mas o mesmo não ocorreu em termos de ocupação feminina dos cargos eletivos, ou seja, parece existir um hiato entre essa medida institucional e o processo de escolha do eleitorado nacional.

Se há polêmicas em torno do mecanismo das cotas, por outro lado, parece razoável supor que as desigualdades encontradas na representação política dos gêneros constituem sérios entraves para a vitalidade das democracias contemporâneas, limitando e condicionando, também, o avanço da promoção da igualdade de gênero em outras áreas da vida social. Por isso mesmo, o tema da sub-representação política de determinados grupos que historicamente sofreram opressões e ocuparam posições desvantajosas na sociedade, dentre os quais as mulheres, estruturou, mais recentemente, um campo pujante de pesquisas no interior das ciências sociais. Particularmente porque o fenômeno obriga, muitas vezes, a construção de abordagens que levem em conta as relações constitutivas entre a política e a cultura, o que desafia o diálogo entre técnicas de pesquisa, conceitos e teorias oriundas de diferentes campos disciplinares.

Com a intenção de contribuir para a compreensão desse complexo fenômeno, apresentamos nesse artigo os resultados de investigação que buscou

\footnotetext{
Esse índice é composto por quatro subíndices: 1) Participação e Oportunidades Econômicas; 2) Educação; 3) Saúde e Sobrevivência; 4) "Empoderamento Político". Maiores informações em http:// www3.weforum.org/docs/WEF_GenderGap_Report_2012.pdf

2 Esse item é avaliado de acordo com os seguintes indicadores: razão mulheres/homens em relação ao total de anos ocupando cargos de presidente/a ou primeira/o ministra/o nos últimos 50 anos; razão mulheres /homens nos cargos ministeriais e razão mulheres/homens ocupando cadeiras no parlamento.
} 
identificar condicionantes das disposições favoráveis (ou contrárias) ao voto em mulheres através de uma interface entre os estudos de cultura política e de comportamento eleitoral. Em termos operacionais, nossa intenção foi verificar em que medida sentimentos partidários positivos em relação aos dois partidos mais expressivos nacionalmente, PT e PSDB, estão relacionados a disposições favoráveis ao voto em mulheres entre os eleitores brasileiros. A base empírica para a investigação foi o Estudo Eleitoral Brasileiro (ESEB, 2010) em sua edição de 2010.

Subjacente a essa proposta está a hipótese de que, apesar da crise de legitimidade e engajamento por que passam as instituições partidárias sociais (Baquero, 2000; Mair, 2003; Witheley, 2011; Mayer, 2011; Dalton, 2013), elas ainda constituem elementos importantes na estruturação dos valores e preferências políticas dos cidadãos em nosso país. A escolha das legendas se deve evidentemente à expressividade que cada uma possui no cenário político nacional em termos de resultados eleitorais, mas também porque possuem uma trajetória de oposição ideológica construída ao longo de décadas de disputas, apesar das reconfigurações e adaptações de ambos perante a conjuntura nacional. Em que pesem essas reconfigurações em prol da "luta eleitoral", nossa expectativa inicial era de que os eleitores que nutrem sentimentos positivos por essas distintas agremiações possuem atitudes e valores políticos significativamente distintos. Tal como Ribeiro, Carreirão e Borba (2011) demonstraram a respeito de temas como estatismo e igualitarismo, nossa intenção é apresentar resultados de testes sobre a relação entre sentimentos partidários e disposições favoráveis à participação feminina na política nacional.

Para além dessa introdução, o texto conta inicialmente com um seção em que procuramos revisar de forma sumária as principais abordagens explicativas da sub-representação feminina e também destacar a relevância de uma dimensão subjetiva do problema. Na sequência, após breves considerações metodológicas, passamos a exposição dos resultados dos testes desenvolvidos. Por fim, procuramos estabelecer uma síntese desses resultados em uma breve conclusão.

\section{A Dimensão Subjetiva do Problema}

A multicausalidade da sub-representação feminina no campo político pode ser vista quase como ponto consensual para a maioria dos analistas envolvidos com o tema. Processos de socialização bastante longos e fortes constrangimentos culturais se combinam com constrangimentos político-institucionais e também sociais na configuração de obstáculos significativos para a presença das mulheres em distintas esferas do poder político. Tais dimensões participariam de uma dinâmica de retroalimentação, ainda que no plano empírico seja viável a sua separação em termos analíticos, já que investigações focalizando todas elas são raras.

Essa separação analítica tem gerado predominantemente estudos sobre os obstáculos ou incentivos institucionais. A pesquisa conduzida por Araújo (2009) pode ser apontada como representante desse grupo, pois procurou investigar a sub-representação feminina no legislativo brasileiro a partir da interrogação, sobretudo, de suas causas político-institucionais. Discutindo a literatura comparada internacional sobre o tema a autora destaca a afirmação de que o sistema eleitoral pode dificultar ou facilitar o acesso das mulheres nos parlamentos quanto a três aspectos: i) ao tipo de representação, que tende ser mais favorável às mulheres quando proporcional; ii) à magnitude dos distritos, sendo que os médios ou grandes oferecem mais chances para a eleição de mulheres; iii) e, finalmente, ao sistema de voto que, quando fundamentado em listas fechadas também favorece as candidaturas femininas. Seu objetivo fundamental passa a ser, então, testar a pertinência dessas afirmações para o contexto brasileiro.

Os dados apresentados pela autora revelam particularidades importantes em nosso país: Estados pequenos, com distritos eleitorais de magnitude menor do que outros em, termos de vagas de representação e de população elegeram mais mulheres em 2006, como o Amapá (4), Espírito Santo (4), Mato Grosso (2), Rio Grande do Norte (2), Amazonas (2) e Roraima (2). Além disso, os resultados mais positivos para as mulheres se deram nas unidades estaduais que apresentam menores índices de desenvolvimento socioeconômicos, o que também contraria a tendência apontada pela bibliografia de estabelecer uma correlação positiva entre cultura política mais igualitária de gênero e modernização socioeconômica. Ao sustentar que a explicação desses dados não pode prescindir da inclusão de outras variáveis ainda localizadas na organização do sistema eleitoral brasileiro, a autora concluiu que eles se devem principalmente à incidência: a) do tamanho e peso dos partidos nos estados, já que as candidaturas femininas foram melhores sucedidas quando pertencentes aqueles de porte grande, e b) da densidade da disputa, entendendo-se por essa a relação existente entre o número de candidaturas e o número de vagas em disputa. Sobre esse último aspecto, sua conclusão é a de que no caso brasileiro 
há uma saturação da oferta que reduz ainda mais as chances de mulheres entrarem na disputa e obterem sucesso nela.

Outros estudos tendem a corroborar essa afirmação, como o de Miguel e Queiroz (2006). Esses autores, considerando as disputas eleitorais municipais ocorridas em 1996, 2000 e 2004, identificaram que o desempenho das candidaturas femininas foi melhor nas regiões com indicadores socioeconômicos mais baixos: Norte, Nordeste e Centro-Oeste. Os autores alertam ainda que esta não é uma tendência nova, já que dados de eleições anteriores apontam para a mesma direção. Ao apresentarem restrições às explicações correntes para esses dados, como a associação das candidatas dessas regiões com partidos de direita, o nível de escolaridade que as beneficiariam e o maior peso de mulheres no eleitorado, os autores afirmam ser necessário incluir novas variáveis que ajudem a compreender o fenômeno. Entre elas, os autores citam o capital político das mulheres eleitas e sua relação com os padrões de associativismo vigente em cada localidade e com a estrutura dos partidos. Tais sugestões, embora incluam o fator associativismo, estão em concordância com as indicações de Araújo (2009) quanto a considerar o peso da estrutura partidária e do próprio capital político das candidaturas num contexto em que a densidade da disputa é alta.

Não se trata aqui de criticar os recortes analíticos desses e outros estudos que se concentram ou enfatizam aspectos institucionais, uma vez que oferecem uma valiosa contribuição para a compreensão de fatores que agem no fenômeno da reduzida presença das mulheres no sistema político brasileiro. Todavia, pretendemos defender que permanece imprescindível seu diálogo com as bases culturais do fenômeno.

Atentos a essa necessidade, um grupo de pesquisas tem se debruçado sobre o que podemos denominar de dimensão subjetiva do problema. Vários dos artigos que compõem o Dossiê - Mulheres na Política, Mulheres no Poder, publicados pela Revista Estudos Feministas, podem ser inseridos nesse grupo, já que nos alertam para a presença de valores culturais que impõe obstáculos no interior dos partidos à participação das mulheres na política institucional, frustrando os resultados esperados da legislação das cotas. Essas pesquisas mostram que as candidaturas femininas enfrentam a falta de apoio financeiro e de recursos materiais a suas campanhas no interior dos partidos, mesmo em situações que demonstram reunir maiores possibilidades de obter sucesso na competição eleitoral diante de candidaturas masculinas. Assim, muitas vezes, a discriminação de gênero se sobrepõe à racionalidade que visa ao sucesso eleitoral, indicando que a reprodução de determinadas concepções culturais estruturam, no interior dos partidos, condições desiguais de competição política entre homens e mulheres (Grossi e Miguel, 2001).

Além disso, muitas mulheres inseridas na política institucional percebem que sua legitimidade nesse espaço está condicionada à capacidade de corresponder a um ideal ainda baseado nos atributos tradicionalmente associados ao gênero feminino, como a maternidade e a beleza. Se elas não se enquadram nesses ideais, reduzem as chances de obter audiência receptiva das eleitoras e dos eleitores, tanto quanto de seus pares no sistema institucional. É importante também mencionar que as mulheres têm mais chances de obter sucesso na competição eleitoral quando disputam cargos legislativos do que quando disputam cargos executivos. Elas enfrentam barreiras culturais para ser aceitas em cargos vistos com maior poder de decisão e comando (Jurema, 2001).

Para uma grande parte das teóricas feministas, as causas dessas barreiras remontam às concepções que forneceram as próprias bases para a construção das instituições políticas modernas. De acordo com a análise de Pateman (1993), por exemplo, o modelo metafórico intelectual que esteve subjacente à organização política das sociedades ocidentais - o modelo do contrato social - fundou-se numa concepção de mundo rigidamente separada entre esfera pública e privada que foi acompanhada e justificada pela atribuição de competências e responsabilidades exclusivas a cada gênero. Nesse modelo, o gênero feminino apareceu, em muitas formulações modernas, identificado explicitamente como aquele que teria a vocação para cuidar da reprodução do mundo privado, enquanto que o masculino, do mundo público. Em outras formulações contemporâneas, longe de desconstruir essa concepção, o silêncio quanto à existência de gêneros contribuiu para a desqualificação política das demandas específicas das mulheres, reforçando a ideia de que seus "assuntos", próprios da vida privada, não teriam status de preocupações públicas.

Como analisa Phillips (1991), encarnadas no arcabouço jurídico e institucional dos Estados modernos, aquelas concepções são por ele ancoradas e perpetuadas. Por isso mesmo, nessa perspectiva, os dados que comprovam a reduzida presença feminina na política não seriam evidências de que as mulheres sejam menos participativas e possuam menor grau de motivação para se inserir em atividades políticas. Tais evidências, ao contrário, seriam sintomas dos processos históricos e culturais que, cristalizados em instituições, dificultam até os dias correntes 
sua participação em partidos políticos e suas possibilidades de êxitos na competição eleitoral.

Defendendo de forma veemente a importância de fatores culturais na explicação da sub-representação feminina nas democracias contemporâneas, um influente grupo de pesquisadores das ciências sociais tem afirmado, entretanto, que este quadro estaria sofrendo importantes mudanças nas últimas décadas. Tal grupo, dedicado aos chamados "estudos de mudança cultural em perspectiva comparada", tem apresentado evidências empíricas de uma alteração nas disposições dos públicos das chamadas sociedades pós-industriais em relação à igualdade de gênero, com efeitos positivos sobre as instituições (Inglehart e Welzel, 2005; Inglehart e Norris, 2003).

Essa reorientação subjetiva estaria associada a uma mudança valorativa maior de caráter humanista e conectada à crescente ênfase na autoexpressão e na tolerância à diversidade (Inglehart, 1977, 2001; Ribeiro, 2007). A emergente defesa da igualdade de gênero nessas sociedades economicamente desenvolvidas estaria associada à crença de que a democracia é uma forma de governo baseada em um contrato entre iguais que se relacionam horizontalmente, logo, incompatível com discriminações sexuais ou raciais (McDonagh, 2002; Welzel, 2003).

O reflexo dessa mudança é a presença constante e relevante da questão do "empoderamento" das mulheres na agenda política de algumas dessas nações (Inglehart, Norris e Welzel, 2002). Esses efeitos, inclusive parecem já ultrapassar os limites dessas sociedades economicamente privilegiadas. Dados da IPU indicam que em países tão distintos como Suécia, Argentina, África do Sul, Uruguai, Estados Unidos e Marrocos já é possível verificar um processo de ampliação da representação feminina. Essa informação não contradiz o quadro anteriormente desenhado por nós, pois a desigualdade de representação entre homens e mulheres continua sendo alarmante. Não obstante, os dados indicam uma tendência à redução das disparidades com diferentes intensidades em diferentes países.

As pesquisas mencionadas como representantes desse segundo grupo, apesar das explícitas diferenças teóricas e metodológicas, se aproximam ao defenderem a relevância de dimensões subjetivas e culturais na explicação do fenômeno da sub-representação feminina nos espaços políticos das modernas democracias.

A pesquisa cujos resultados apresentamos a seguir compartilha da preocupação com essa ordem de fatores, filiando-se assim ao que podemos chamar de abordagem culturalista. Todavia, nossa proposta de análise se diferenciou dessas iniciativas ao propor uma interação entre essa abordagem e os estudos sobre a relação entre partidos e eleitores. Interessava-nos, é claro, identificar as orientações subjetivas dos eleitores em relação às candidaturas femininas, mas nosso foco principal recaiu sobre a maneira como essas orientações eram afetadas pelos sentimentos desse eleitorado em relação aos principais partidos nacionais.

Essa proposta nos remete aos estudos sobre a identificação entre eleitores e partidos políticos, cujas principais perspectivas analíticas seriam a Escola de Michigan e a teoria da escolha racional. ${ }^{3}$ Na primeira abordagem a identificação partidária (IP) originar-se-ia de uma adesão de base psicológica aos partidos constatada por meio de dados de surveys sobre comportamento eleitoral. Tratar-se-ia de uma identidade forjada em bases afetivas no processo de socialização (Ribeiro, Carreirão e Borba, 2011). Como salienta Figueiredo (1991: 37), a tese é a de que,

[...] uma vez formada, a identificação partidária tende a tornar-se estável, ou seja, os eleitores que têm identificação partidária em graus variados inclinam-se a 'ver' a política e orientar suas ações numa direção partidária [...].

Para a segunda abordagem os partidos (e as ideologias políticas) são "atalhos cognitivos" utilizados pelos eleitores para reduzir os custos inerentes à busca e processamento das informações necessárias para a efetivação de escolhas eleitorais (Downs, 1997). Em síntese:

Observando em algumas ocasiões que um partido se comporta em conformidade com seus interesses (ou defendendo certas ideias mais do que outros), o eleitor pode, em uma próxima eleição, utilizar esse conhecimento prévio para decidir seu voto, economizando recursos (especialmente tempo) para se informar e fazer sua escolha (Ribeiro, Carreirão e Borba, 2011: 338).

Não se trataria, portanto, de uma identificação afetiva ou normativamente fundada, como preconiza a Escola de Michigan. Na medida em que procuramos identificar o impacto de determinados sentimentos partidários sobre as atitudes dos eleitores em relação à inserção das mulheres na política, nos afastamos da perspectiva racionalista e nos aproximamos de uma concepção que entende a identificação partidária como formada a partir de processos de socialização prolongados. Os identificados com o partido $\mathrm{X}$ ou $\mathrm{Y}$, após a consolidação dessa identificação, tenderiam a

\footnotetext{
Sobre essas teorias, ver Figueiredo (1991) e Castro (1992), dentre outros.
} 
ver a política sob a ótica desses respectivos partidos. Como elertaram os autores citados anteriormente, esse tipo de hipótese padece de uma séria limitação metodológica, já que depende de dados de survey que não possibilitam estabelecer relações de causalidade (Ribeiro, Carreirão e Borba, 2011). Apesar desse problema, possivelmente contornável apenas com o emprego de metodologia experimental ${ }^{4}$, nos propusemos a explorar a plausibilidade desse tipo de relação com procedimentos de análise bivariada e multivariada que tomam como variáveis dependentes as orientações e atitudes dos eleitores à respeito de candidaturas femininas a cargos eletivos e como variáveis independentes os seus sentimentos partidários pelo PT e PSDB.

\section{Sentimentos Partidários e Igualdade de Gênero}

O principal objetivo da pesquisa cujos resultados agora apresentamos foi identificar a existência de associações positivas ou negativas entre sentimentos partidários pelo PT e PSDB e disposições favoráveis à igualdade de gênero no campo político. Os dados utilizados para tanto foram extraídos do ESEB 2010, que felizmente contém variáveis relativas às disposições dos eleitores nacionais em relação aos partidos políticos e também um conjunto interessante de medidas sobre valores e atitudes relacionadas à temática da presença feminina em diferentes esferas da vida nacional.

Tanto na concepção do problema de pesquisa, quanto na definição dos procedimentos para operacionalizar os testes, o trabalho já citado de Ribeiro, Carreirão e Borba (2011) foi de fundamental importância. Nesse artigo os pesquisadores propõem uma medida integrada de sentimentos partidários (uma espécie de índice) resultado da combinação de duas variáveis geradas pelas seguintes questões: 1) existe algum partido que representa a forma como o(a) Sr.(a) pensa? e 2) existe algum partido que o(a) Sr.(a) goste? A partir destes procedimentos esses autores realizam uma série de análises multivariadas com o objetivo de verificar o impacto desse índice sobre diferentes atitudes políticas (democratismo, estatismo, igualitarismo) e também sobre o comportamento eleitoral dos brasileiros.

A junção das duas variáveis relativas aos partidos ("gosta" e "representa o pensamento") proposta por

\footnotetext{
${ }^{4}$ Sobre os modelos de causalidade baseados em metodologia experimental ver Experimental Political Science and Study of Causality, de Rebecca Morton e Kenneth Willians (Morton e Williams, 2010).
}

esses autores é justificável em razão da variedade de testes que conduzem, tornando indesejável a duplicação do número de testes que o emprego de cada medida em separado acarretaria. Desta forma, através de técnicas de redução de dimensionalidade (análise fatorial e de consistência interna), encontraram respaldo estatístico para essa combinação em um único indicador.

De forma distinta, no presente trabalho propomos um retorno às variáveis originais em análises isoladas, ou seja, utilizamos nos testes a variável "gosta" e "representa o pensamento" sem a sua junção em índice. Sustentamos esse retorno em duas razões fundamentais. A primeira delas diz respeito à limitação do presente trabalho a uma única dimensão supostamente relacionada aos sentimentos partidários, a saber, as disposições em relação à igualdade de gênero. Diferentemente dos autores mencionados acima, que discutiram a relação entre tais sentimentos e três diferentes dimensões atitudinais, a redução a apenas um eixo temático torna viável a análise individualizada, sem multiplicar demasiadamente o número de testes necessários. A segunda razão, de natureza mais substantiva, diz respeito a possíveis distinções dos efeitos dessas variáveis partidárias em relação às disposições favoráveis ou contrárias à igualdade de gênero na política. Apesar da variável "gosta" e "representa o pensamento" se relacionarem a essa ligação subjetiva entre eleitores e partidos, é possível levantar a hipótese de que elas medem níveis distintos dessa relação. Recorrendo ao clássico The Civic Culture, de Almond e Verba (1963), podemos vincular a primeira dessas medidas ao grupo das orientações afetivas, enquanto a segunda seria melhor compreendida como componente do grupo de orientações cognitivas. Ou seja, enquanto essa última pressupõe um conhecimento, ainda que parcial, do conteúdo programático dos partidos e também a compreensão das ideias que compõem o pensamento dos seus membros, a primeira não pressupõe necessariamente qualquer exercício cognitivo dessa natureza. O "gostar", portanto, pode ter como fundamento uma ligação puramente afetiva que não se vincula necessariamente a dimensões cognitivas. Ao realizar a junção dessas duas variáveis em um único indicador, perde-se a oportunidade de identificar possíveis efeitos distintos desses níveis distintos de ligação subjetiva.

Antes, porém, de passarmos à exposição dos nossos resultados, precisamos reconhecer uma limitação importante do trabalho que, em razão principalmente da base empírica utilizada, não pode 
ser superada ${ }^{5}$. Ribeiro, Carreirão e Borba (2011) demonstraram que os sentimentos partidários estão fortemente associados às escolhas eleitorais dos brasileiros. Através de modelos multivariados esses pesquisadores verificaram que os sentimentos positivos/negativos em relação ao PT/PSDB são fortes preditores do voto, considerando as últimas eleições presidenciais. Esses resultados atestam a relevância dessa adesão subjetiva às instituições partidárias sobre o comportamento eleitoral dos brasileiros, entretanto, coloca um sério problema ao modelo de análise que agora propomos. Isso em razão do PT ter apresentado uma mulher como concorrente ao cargo presidencial, enquanto o PSDB lançou um homem à disputa. Diante desse cenário concreto é possível levantar a hipótese de que as disposições individuais favoráveis ao voto em mulheres possam ter sido influenciadas pela candidatura feminina do PT, ou seja, pode-se argumentar que não são os sentimentos partidários positivos pelo PT ou PSDB que estão relacionados a disposições mais favoráveis às candidaturas femininas, mas que tais disposições foram geradas fortemente por essa decisão de um dos partidos de lançar uma mulher na disputa.

Esse argumento opõe em um único modelo uma variável independente conjuntural (candidatura específica) à outra de natureza atitudinal (sentimentos partidários), essa última supostamente forjada ao longo de processo relativamente longo de socialização política. A variável dependente, neste caso, seria a disposição favorável às candidaturas femininas que poderiam ser resultado, portanto, de uma escolha conjuntural do eleitor motivada pela decisão de um dos partidos em disputa ou uma disposição com raízes mais profundas, que pode ou não estar relacionada a sentimentos partidários.

No plano empírico os efeitos desses dois condicionantes poderiam ser testados e comparados com a inclusão de indicadores correspondentes em modelos multivariados. Seria possível incluir como variável de controle dos efeitos das medidas de sentimentos partidários a variável "voto no primeiro turno", como uma proxy da concordância dos eleitores em relação à candidatura feminina do PT. Entretanto, em razão da forte associação entre tais sentimentos e as escolhas eleitorais (Ribeiro, Carreirão e Borba, 2011), esse procedimento não é aconselhável em razão da colinearidade dos preditores. Mesmo que a colinearidade não fosse considerada um problema, não seria possível afirmar qual das duas variáveis estaria "roubando" efeito da outra. Ou seja, não é viável sob o ponto de vista técnico concluir em um mesmo modelo essas variáveis que, provavelmente, sejam igualmente relevantes na explicação de nossa variável dependente. Esse obstáculo técnico poderia ser contornado com a construção de modelos em que esses preditores fossem incluídos separadamente, seguida da comparação dos efeitos, no entanto, em termos substantivos persistiria o problema, pois em razão da forte associação entre as variáveis não poderíamos afirmar com certeza qual delas é a mais relevante.

A solução para esse dilema só seria possível com a condução das análises que propomos tomando como base empírica dados sobre contextos eleitorais em que nenhum dos partidos considerados tenha lançado mulheres na disputa ao cargo em questão, como os de 2002 e 2006. Neste caso, bastaria verificar se os efeitos dos sentimentos continuam ocorrendo nesses momentos em que está ausente essa outra variável independente concorrente (candidatura feminina). Isso infelizmente também não é viável, já que o ESEB, em suas edições de 2002 e 2006 (Almeida et al. 2004; ESEB, 2006), não incluía a pergunta sobre disposição para votar em mulheres.

Em síntese, reconhecemos que o contexto particular da última eleição presidencial e as características dos dados utilizados impõem essa limitação do trabalho e esperamos que no futuro próximo esse problema possa ser contornado com a continuidade dos testes que propomos.

Tendo em mente esse quadro, consideramos primeiramente a variável "gosta do PT", codificada como uma escala de 11 pontos partindo do "não gosta" e chegando ao "gosta muito", e analisamos a relação desses posicionamentos com um conjunto de disposições através de testes de associação Gamma (Tabela 1). A primeira variável diz respeito à disposição para votar em mulheres para cargos majoritários. As demais foram obtidas por meio da identificação da concordância ou discordância dos entrevistados em relação a afirmações sobre o assunto seguindo a seguinte escala de quatro pontos: 1 = discorda muito, 2 = discorda, 3 = concorda, 4 = concorda muito ${ }^{6}$.

Destacamos inicialmente que todos os testes resultaram em níveis de significância estatística compatíveis com o limite usualmente utilizada em investigações da área, ou seja, 0,05. O primeiro dos testes indicou uma forte associação entre gostar do PT e estar disposto a votar em mulheres, já que o valor de $\gamma$ atingiu .56, marco pouco usual em estudos

\footnotetext{
5 Agradecemos ao parecerista anônimo que nos alertou sobre a necessidade de incorporar essa questão do trabalho.
} 
Tabela 1. Associações entre "gostar do PT" e atitudes em relação à igualdade de gênero na política.

\begin{tabular}{lcc}
\hline \multicolumn{1}{c}{ Variável } & $\gamma$ & Sig. \\
\hline Votaria em uma mulher para cargo majoritário & 0,562 & 0,000 \\
Em geral os homens são mais adequados para a carreira política & $-0,062$ & 0,020 \\
Em geral os homens governam melhor do que as mulheres & $-0,055$ & 0,050 \\
As mulheres ainda não possuem experiência política suficiente & $-0,069$ & 0,010 \\
\hline
\end{tabular}

Fonte: ESEB (2010)/ N=2000.

Tabela 2. Associações entre "gostar do PSDB" e atitudes em relação à igualdade de gênero na política.

\begin{tabular}{lcc}
\hline \multicolumn{1}{c}{ Variável } & $\gamma$ & Sig. \\
\hline Votaria em uma mulher para cargo majoritário & $-0,545$ & 0,001 \\
Em geral os homens são mais adequados para a carreira política & 0,101 & 0,000 \\
Em geral os homens governam melhor do que as mulheres & 0,091 & 0,002 \\
As mulheres ainda não possuem experiência política suficiente & 0,098 & 0,000 \\
\hline
\end{tabular}

Fonte: ESEB (2010)/ N=2000.

sobre atitudes e comportamento político. Os demais testes retornaram valores bem menores, mas ainda assim na direção esperada e com significância aceitável. Posicionamentos favoráveis a esse partido são acompanhados de crescente discordância em relação à afirmação de que os homens são mais adequados para a carreira política, como indica o sinal negativo do coeficiente. $\mathrm{O}$ mesmo ocorre em relação à afirmação de que os homens governam melhor do que as mulheres. Finalmente, a situação é semelhante no caso da afirmação de que as mulheres ainda não possuem experiência política suficiente. Em síntese, o que podemos chamar de petismo, medida pela escala de "gostar" do PT está associado a posturas mais favoráveis ao que podemos chamar de empoderamento político feminino, já que se relacionada à intenção de voto em mulheres e à rejeição das afirmações mencionadas anteriormente.

Os resultados encontrados quando os testes envolvem a variável "gostar" do PSDB são semelhantes aos anteriores, porém com sentidos inversos (Tabela 2). Primeiro a escala de "gostar" desse partido está negativamente associada à intenção de voto em mulheres para cargos majoritários, como aponta o expressivo coeficiente negativo de $-0,54$. Todos os demais coeficientes são positivos, indicando que avanços na escala do "gostar" são acompanhados de maior concordância em relação às afirmações. Mais especificamente, progressões nessa escala estão associadas à aceitação de que os homens são mais adequados para a política, são melhores governantes e também à concordância em relação à falta de experiência política das mulheres. Em resumo, a postura dos que gostam dessa agremiação partidária tendem a ser contrária ao empoderamento de que estamos tratando.

A segunda variável relativa aos sentimentos partidários diz respeito à identificação do PT e PSDB como partidos que melhor representam a forma como os entrevistados pensam ${ }^{7}$. Começando pela medida que envolve o primeiro partido (Tabela 3 ), o primeiro teste segue a direção dos resultados envolvendo a medida anterior de "gostar", pois verificamos que essa identificação com o PT está associada de maneira positiva e forte $(0,61)$ com a disposição para votar em mulheres. Os três outros testes dessa tabela, entretanto, se diferenciam bastante dessa situação, pois nenhum deles atingiu os níveis de significância estatística necessários.

Passando aos testes envolvendo a variável sobre a identificação com o PSDB (Tabela 4), o primeiro resultado é consistente com o exposto até aqui. Aqueles que identificam esse partido como aquele que representa a forma como pensam tendem a manifestar disposição contrária ao voto em mulheres, como indica o coeficiente negativo de 0,57. Dos três testes seguintes, dois deles apresentam níveis de significância aceitáveis e coeficientes positivos. Esse tipo de identificação com o PSDB está associado positivamente com a concordância em relação às afirmações "os homens são mais adequados para a carreira política" e "as mulheres ainda não possuem experiência política suficiente".

\footnotetext{
$\overline{7}$ As recodificações realizadas são descritas no Apêndice Metodológico.
} 
Tabela 3. Associações entre "PT como partido que representa sua forma de pensar" e atitudes em relação à igualdade de gênero na política.

\begin{tabular}{lcc}
\hline \multicolumn{1}{c}{ Variável } & $\gamma$ & Sig. \\
\hline Votaria em uma mulher para cargo majoritário & 0,610 & 0,000 \\
Em geral os homens são mais adequados para a carreira política & $-0,034$ & 0,451 \\
Em geral os homens governam melhor do que as mulheres & $-0,043$ & 0,355 \\
As mulheres ainda não possuem experiência política suficiente & $-0,054$ & 0,217 \\
\hline
\end{tabular}

Fonte: ESEB (2010)/ N=2000.

Tabela 4. Associações entre "PSDB como partido que representa sua forma de pensar" e atitudes em relação à igualdade de gênero na política.

\begin{tabular}{lcc}
\hline \multicolumn{1}{c}{ Variável } & $\gamma$ & Sig. \\
\hline Votaria em uma mulher para cargo majoritário & $-0,577$ & 0,001 \\
Em geral os homens são mais adequados para a carreira política & 0,184 & 0,034 \\
Em geral os homens governam melhor do que as mulheres & 0,159 & 0,078 \\
As mulheres ainda não possuem experiência política suficiente & 0,187 & 0,031 \\
\hline
\end{tabular}

Fonte: ESEB (2010)/ N=2000.

Como é possível verificar a partir dos dados expostos até esse momento, as associações entre variáveis partidárias e as relativas ao voto em mulheres são bastante consistentes, indicando que sentimentos positivos em relação à PT e PSDB estão relacionados a posições bastante distintas. Essa relação é menos robusta no que diz respeito às demais variáveis sobre a inserção feminina na política, o que fica claro com a observação de valores reduzidos para alguns testes de associação e ausência de significância estatística em outros. Ainda assim, em termos gerais parece ser plausível afirmar que essas medidas de "petismo" e "tucanismo" estão associadas às posturas mais (no primeiro caso) ou menos (no segundo caso) favoráveis ao empoderamento feminino.

Para confirmar essas relações, propomos agora modelos multivariados de regressão logística que estimam os efeitos das variáveis de sentimento partidário sobre as demais medidas. Começamos pela análise dos efeitos dessas variáveis sobre a probabilidade dos indivíduos fazerem parte do grupo de entrevistados que manifestaram disposição favorável ao voto em mulheres. Essa técnica de análise permite que sejam testados os efeitos das variáveis de "petismo" e "tucanismo" juntas e também o controle desses impactos por variáveis demográficas, como sexo, escolaridade, idade e renda.

Utilizando como variáveis preditoras primeiramente aquelas que se referem ao "gostar" dos partidos, o primeiro modelo proposto retornou os resultados expostos abaixo (Tabela 5). Primeiramente é preciso
Tabela 5. Modelo de regressão logística para voto em mulheres usando a variável partidária "gosta" PT e PSDB.

\begin{tabular}{lccc}
\hline \multicolumn{1}{c}{ Variáveis } & B & Sig. & Exp. (B) \\
\hline Sexo & 0,204 & 0,314 & 1,227 \\
Idade & 0,000 & 0,974 & 1,000 \\
Escolaridade (Níveis) & 0,178 & 0,002 & 1,195 \\
Renda familiar (Faixas) & 0,184 & 0,088 & 1,202 \\
Gosta PT & 0,257 & 0,000 & 1,293 \\
Gosta PSDB & $-0,103$ & 0,001 & 0,902 \\
Constant & 0,379 & 0,550 & 1,461 \\
\hline
\end{tabular}

Fonte: ESEB (2010)/N=2000.

destacar o baixo rendimento explicativo das variáveis de controle na presença das medidas partidárias, uma vez que apenas a escolaridade dos entrevistados, medida em níveis, se mostrou relevante e seu $\exp (\mathrm{B})$ de 1,195 indica que cada nível adicional eleva a probabilidade de estar entre os que votariam em uma mulher em 19,5\%. Os efeitos das variáveis partidárias foram confirmados nos sentidos apontados pela análise bivariada inicial. Podemos primeiramente notar que elevações na escala que mede os sentimentos positivos pelo PT produzem incremento de $29,3 \%$ na probabilidade de manifestar disposição favorável ao voto em mulheres. Contrariamente, sentimentos positivos sobre o PSDB provocam efeito redutor de $9,8 \%$ nessa mesma probabilidade. 
O segundo modelo que propomos envolve procedimento semelhante, porém substituindo a variável do "gosta" pela medida relacionada à identificação dos partidos com a forma de pensar dos entrevistados (Tabela 6).

Os efeitos novamente são bastante consistentes, inclusive no que diz respeito aos atributos demográficos, pois a escolaridade continua sendo a única medida com efeito significativo, confirmando que os mais escolarizados tem maior probabilidade $(15,2 \%)$ de compor o grupo dos que se posicionam favoravelmente ao voto em mulheres. As variáveis de sentimentos partidários confirmam novamente os efeitos do "petismo" e do "tucanismo" sobre essa disposição eleitoral. No primeiro caso o efeito é positivo e bastante expressivo, elevando a probabilidade em mais de $260 \%$. No segundo o efeito é negativo, reduzindo essa mesma probabilidade em quase $70 \%$. É importante informar que desta vez as variáveis de sentimentos são dicotômicas, portanto o seu impacto se dá em uma única vez e não de forma cumulativa como na escala usada na variável anterior sobre "gostar" do PT e PSDB.

Tabela 6. Modelo de regressão logística para voto em mulheres usando a variável partidária "representa sua forma de pensar".

\begin{tabular}{lccc}
\hline \multicolumn{1}{c}{ Variáveis } & B & Sig. & Exp. (B) \\
\hline Sexo & 0,112 & 0,554 & 1,118 \\
Idade & $-0,002$ & 0,740 & 0,998 \\
Escolaridade (Níveis) & 0,141 & 0,009 & 1,152 \\
Renda familiar (Faixas) & 0,086 & 0,388 & 1,090 \\
Pensa PT & 1,298 & 0,000 & 3,663 \\
Pensa PSDB & $-1,174$ & 0,000 & 0,309 \\
Constant & 1,618 & 0,003 & 5,041 \\
\hline
\end{tabular}

Fonte: ESEB (2010)/N=2000.
Os resultados desses dois modelos constituem evidências sobre os efeitos dessas disposições, que estamos denominando genericamente de sentimentos partidários, e a manifestação de posturas favoráveis ao voto em mulheres para cargos majoritários no cenário nacional. "Petistas" e "tucanistas" consistentemente manifestam posturas distintas em relação a esse aspecto mesmo diante do controle de variáveis demográficas clássicas.

Continuando nesse mesmo itinerário analítico, procedimentos semelhantes são adotados tomando como variáveis dependentes aquelas medidas geradas pela identificação das concordâncias e discordâncias dos participantes da pesquisa acerca das três afirmações já mencionadas anteriormente. Entretanto, ao invés de analisar isoladamente cada uma dessas três variáveis, propomos agora uma procedimento alternativo que consiste na combinação das mesmas em um Índice de Apoio ao Empoderamento Feminino (IAEF). A construção de tal índice é justificada em termos estatísticos pelos resultados de análise fatorial conduzida com o objetivo de reduzir a dimensionalidade das três medidas a uma única medida, bem como pelo teste Alpha de Cronbach (Hair, Anderson e Tatham, 1988) (Tabela 7). Como as três variáveis originais tem sentido negativo, já que as concordâncias são codificadas com pontuação positiva e indicam posturas desfavoráveis à inserção feminina na política, após a computação do índice procedemos a sua inversão. $\mathrm{O}$ resultado final desses procedimentos é uma medida com 10 pontos, de 0 a 9.

$\mathrm{O}$ índice proposto é codificado como uma escala e possui distribuição normal (assimetria de 0,760), portanto, o procedimento multivariado adotado foi a regressão linear múltipla composto pelas variáveis de sentimento partidário e as medidas de controle já utilizadas nos testes anteriores. O modelo contendo a variável "gosta" tem os seus resultados apresentados

Tabela 7. Análise fatorial e teste alpha para as variáveis sobre gênero e política.

\begin{tabular}{lc}
\hline \multicolumn{1}{c}{ Variável } & $\begin{array}{c}\text { Carga Fatorial } \\
\text { Componente 1 }\end{array}$ \\
\hline Em geral os homens são mais adequados para a carreira política & 0,935 \\
Em geral os homens governam melhor do que as mulheres & 0,936 \\
As mulheres ainda não possuem experiência política suficiente & 0,887 \\
\% de variação explicada com 1 componente=84,54 & \\
KMO 0,735 & \\
Alpha 0,908 & \\
\hline
\end{tabular}

Fonte: ESEB (2010). 
abaixo (Tabela 8) e indica que, dentre as variáveis demográficas, apenas sexo e renda familiar provocam efeitos estatisticamente significativos e com sentido positivo. As duas variáveis partidárias, mesmo com a presença das variáveis de controle, se revelaram preditores importantes e os sentidos dos coeficientes confirmam os resultados das análises bivariadas apresentadas anteriormente. Elevações na escala de sentimento pelo PT produz elevação na pontuação do IAEF, enquanto sentimentos mais favoráveis ao PSDB reduzem esse escore. É importante lembrar que nossa intenção com esse modelo não é produzir uma explicação consistente sobre a variável dependente, mas sim testar a consistência do relacionamento entre os sentimentos partidários e as disposições favoráveis ao voto em mulheres com a presença de controles sóciodemográficos fundamentais.

Substituindo a variável "gosta" pela medida "representa a sua forma de pensar", também identificamos congruência com os resultados

Tabela 8. Modelo de regressão linear para índice de apoio ao empoderamento feminino usando a variável partidária "gosta", PT e PSDB.

\begin{tabular}{lccc}
\hline \multicolumn{1}{c}{ Variáveis } & B & Sig. & Beta \\
\hline Constante & 5,187 & 0,000 & \\
Sexo & 0,505 & 0,000 & 0,113 \\
Idade & $-0,007$ & 0,074 & $-0,050$ \\
Escolaridade (Níveis) & 0,031 & 0,988 & 0,323 \\
Renda familiar (Faixas) & 0,228 & 0,000 & 0,114 \\
Gosta PT & 0,060 & 0,000 & 0,092 \\
Gosta PSDB & $-0,078$ & 0,000 & $-0,109$ \\
$\mathrm{R}^{2}=0,048$ & & & \\
\hline
\end{tabular}

Fonte: ESEB (2010).

Tabela 9. Modelo de regressão linear para índice de apoio ao empoderamento feminino usando a variável partidária "representa sua forma de pensar", PT e PSDB.

\begin{tabular}{lccc}
\hline \multicolumn{1}{c}{ Variáveis } & B & Sig. & Beta \\
\hline Constante & 5,255 & 0,000 & \\
Sexo & 0,476 & 0,000 & 0,107 \\
Idade & $-0,006$ & 0,131 & $-0,041$ \\
Escolaridade (Níveis) & 0,033 & 0,266 & 0,033 \\
Renda familiar (Faixas) & 0,201 & 0,000 & 0,101 \\
Pensa PT & 0,149 & 0,245 & 0,029 \\
Pensa PSDB & $-0,736$ & 0,001 & $-0,082$ \\
$\mathrm{R}^{2}=0,033$ & & & \\
\hline
\end{tabular}

Fonte: ESEB (2010). apresentados no início dessa seção. Quanto aos atributos demográficos, apenas sexo e renda continuam aparecendo como preditores, ambos afetando positivamente o índice. Dentre as variáveis de sentimentos partidários, a relacionada ao PT não atingiu o nível de significância necessário, ou seja, ter essa identificação "petista" não altera a pontuação individual no IAEF. Manifestar o sentimento "tucanista", por sua vez, afeta de forma negativa essa mesma pontuação.

\section{Considerações Finais}

Vinculando-se ao que podemos chamar de abordagem culturalista, a pesquisa cujos resultados apresentamos nesse artigo procurou analisar a relação entre os sentimentos que o público brasileiro nutre em relação aos dois principais partidos nacionais e algumas de suas disposições em relação à presença e participação da mulher no cenário político. Neste sentido, a investigação procurou combinar o interesse pelos estudos dos partidos como instituições capazes de condensar valores e disposições subjetivas em seus simpatizantes ou identificados e a preocupação com os condicionantes subjetivos da sub-representação feminina em nosso país.

Nosso pressuposto inicial era a de que, apesar da documentada crise dos partidos políticos como instituição de representação em termos globais (Baquero, 2000; Mair, 2003; Witheley, 2011; Mayer, 2011; Dalton, 2013), os partidos continuam sendo relevantes ao menos no que diz respeito a essa adesão de natureza psicológica e cultural dos eleitores ao conjunto de valores e princípios que diferenciam uma agremiação de outra. Essa pressuposição parece compatível com os resultados que encontramos, pois em vez de uma dispersão aleatória das atitudes investigadas entre os partidários de PT e PSDB, verificamos uma divisão bastante clara entre esses dois grupos fundamentais. O conjunto dos testes revelou que o atributo "ser petista" ou "ser tucanista", nos termos utilizados aqui para esse enquadramento, está associado de forma consistente com um posicionamento específico sobre questões relacionadas à temática do empoderamento feminino.

Como a seção anterior mostrou, indivíduos que nutrem sentimentos positivos pelo PT manifestam valores mais favoráveis em relação a diferentes dimensões desse empoderamento, enquanto aqueles identificados com o PSDB tendem a se posicionarem menos favoravelmente. Neste sentido, esse trabalho confirma dados apresentados por Ribeiro, Carreirão e Borba (2011) que encontraram associações semelhantes focalizando dimensões distintas das atitudes dos eleitores, como igualitarismo, estatismo e democratismo. Tanto esse trabalho anterior como 
o que agora apresentamos, mais do que explicitar diferenças relevantes entre públicos identificados com distintos partidos, apontam para a relevância dos partidos políticos na atual ordem política nacional em um aspecto de suma importância: a cultura política. Diante das constantes críticas, vindas não apenas da imprensa especializada, sobre uma suposta perda de conteúdo ideológico dos partidos nacionais é importante demonstrar que tais instituições ainda não perderam suas especificidades valorativas, ao menos quando avaliamos o reflexo dessas particularidades em distinções fundamentais na cultura política do seu público identificado.

Contudo, como reconhecemos anteriormente, as conclusões do trabalho precisam ser confirmadas com a continuidade de pesquisas no contexto das próximas eleições nacionais, sobretudo porque no pleito de 2010 a candidatura de Dilma Rousseff pelo PT pode ter influenciado de maneira significativa a postura de petistas (positivamente) e tucanistas (negativamente) em relação ao tema do empoderamento feminino.

Seria interessante, portanto, seguir verificando, inclusive em outros níveis (estadual e municipal), como os sentimentos partidários influenciam essa dimensão relevante das atitudes e orientações subjetivas dos brasileiros. A disponibilidade de dados sobre outras nações, sobretudo as cobertas pelo projeto Comparative Study of Electoral Systems (CSES), gera inclusive a possibilidade de que os achados aqui apresentados sejam confirmados ou refutados em contextos culturais, políticos e econômicos distintos.

Por fim, ultrapassando os limites da disputa PT/ PSDB, pode ser interessante ampliar essa discussão incorporando outros partidos com representação importante no cenário nacional, especialmente PV e PMDB. Apesar da inevitável complexificação metodológica que essa expansão metodológica acarretaria, acreditamos que seja um esforço frutífero.

\section{Referência}

Almeida, Alberto Carlos; Cheibub, Zairo; Lourenço, Fernando e Meneguello, Rachel. (orgs.). 2004. ESEB: Estudo Eleitoral Brasileiro, 1998-2002 (Banco de dados). Campinas: UNICAMP. In: Consórcio de Informações Sociais. Disponível em: <http://www. cis.org.br>. Acesso em: 23 ago. 2013.

Almond, Gabriel e Verba, Sydney. 1963. The Civic Culture: Political Attitudes and Democracy in Five Nations. Princeton: Princeton University Press.

Araújo, Clara. 2001. Potencialidades e limites da política de cotas no Brasil. Revista Estudos Feministas, 9(1): 231-253. http://dx.doi.org/10.1590/ S0104-026X2001000100014
Araújo, Clara. 2009. Gênero e acesso ao poder legislativo no Brasil: as cotas entre as instituições e a cultura. Revista Brasileira de Ciência Política, 1(2): 23-59.

Baquero, Marcello. 2000. A vulnerabilidade dos partidos políticos e a crise da democracia na América Latina. Porto Alegre: Editora da UFRGS.

Castro, Mônica Mata Machado de. 1992. Sujeito e estrutura no comportamento eleitoral. Revista Brasileira de Ciências Sociais, 20: 7-19.

Dalton, Russell. 2013. The apartisan American: dealignment and changing electoral politics. Washington: Sage.

Downs, Anthony. 1957. An economic theory of democracy. New York: Harper \& Row Publishers.

Estudo Eleitoral Brasileiro - ESEB, 2006. (Banco de dados). 2010. In: Consórcio de Informações Sociais. Disponível em: <http://www.cis.org.br>. Acesso em: 23 ago. 2010.

Estudo Eleitoral Brasileiro - ESEB, 2010. (Banco de dados). 2012. In: Consórcio de Informações Sociais. Disponível em: <http://www.cis.org.br>. Acesso em: 23 ago. 2013.

Figueiredo, Marcus. 1991. A Decisão do Voto: (democracia e racionalidade). São Paulo: Ed. Sumaré/ANPOCS.

Grossi, Mírian Pillar e Miguel, Sônia Malheiros. 2001. Transformando a diferença: as mulheres na política. Revista Estudos Feministas, 9(1): 167-206. http:// dx.doi.org/10.1590/S0104-026X2001000100010

Hair, Joseph; Anderson, Rolph; Tatham, Ronald. 1984. Multivariate data analysis. New York: Macmillan Publishing.

Hausmann, Ricardo; Tyson, Laura e Zahidi, Saadia. 2012. The Global Gender Gap Report 2012. World Economic Forum. Disponível em: <http://www3. weforum.org/docs/WEF_GenderGap_Report_2012. pdf>. Acesso em: 27 mar. 2013.

Inglehart, Ronald. 1977. The Silent Revolution: Changing Values and Political Styles among Western Publics. Princeton: Princeton University Press.

Inglehart, Ronald. 2001. Modernización y posmodernización: el cambio cultural, económico y político en 43 sociedades. Madrid: Centro de Investigaciones Sociológicas/Siglo Veintiuno.

Inglehart, Ronald e Norris, Pippa. 2003. Rising Tide: Gender Equality and Cultural Change Around the World. Cambridge: Cambridge University Press. http://dx.doi.org/10.1017/CBO9780511550362

Inglehart, Ronald; Norris, Pippa e Welzel, Christian. 2002. Gender equality and democracy. Comparative sociology, 1(3/4): 321-345. http:// dx.doi.org/10.1163/156913302100418628

Inglehart, Ronald e Welzel, Christian. 2005. Modernization, cultural change, and democracy: the human development sequence. New York: Cambridge University Press. 
Jurema, Solange Bentes. 2001. Ações e estratégias do CNDM para o 'empoderamento' das mulheres. Revista Estudos Feministas, 9(1): 207-212. http:// dx.doi.org/10.1590/S0104-026X2001000100011

Mair, Peter. 2003. Os partidos políticos e a democracia. Revista Análise Social, 38(167): 277-293.

Mayer, Rodrigo. 2011. Os Partidos como organizações: um estudo comparado do PSDB \& PT. Dissertação de mestrado, Universidade Federal do Paraná.

McDonagh, Eileen. 2002. Political citizenship and democratization: the gender paradox. American Political Science Review, 96(3): 535-552. http:// dx.doi.org/10.1017/S000305540200031X

Miguel, Luis Felipe e Queiroz, Cristina Monteiro de. 2006. Diferenças regionais e o êxito relativo de mulheres em eleições municipais no Brasil. Revista Estudos Feministas, 14(2): 363-385. http://dx.doi. org/10.1590/S0104-026X2006000200003

Morton, Rebecca e Williams, Kenneth. 2010. Experimental Political Science and the Study of Causality. NY: Cambridge University Press.

Norris, Pippa. 2011. Democratic Deficit. New York: Cambridge University Press. http://dx.doi. org/10.1017/CBO9780511973383
Pateman, Carole. 1993. O contrato Sexual. Rio de Janeiro: Paz e Terra.

Phillips, Anne. 1991. Engendering democracy. Cambrigde: Polity Press.

Ribeiro, Ednaldo Aparecido; Carreirão, Yan e Borba, Julian. 2011. Sentimentos partidários e atitudes políticas entre os brasileiros. Opinião Pública, 17(2): 333-368. http://dx.doi.org/10.1590/ S0104-62762011000200003

Ribeiro, Ednaldo Aparecido. 2007. A consistência das medidas de pós-materialismo: testando a validade dos índices propostos por R. Inglehart no contexto brasileiro. Sociedade e Estado, 22(2): 371-400. http:// dx.doi.org/10.1590/S0102-69922007000200006

Welzel, Christian. 2003. Effective democracy, mass culture, and the quality of elites: the human development perspective. International Journal of Comparative Sociology, 43(3-5): 317-349. http:// dx.doi.org/10.1177/002071520204300306

Witheley, Paul. 2011. Is the party over? The decline of party activism and membership across the Democratic World. Party Politics, 17(21): 21-44. http://dx.doi. org/10.1177/1354068810365505 
Apêndice metodológico:

\section{1) "Gostar do PT" e "Gostar do PSDB"}

Identificação na Base de Dados: ESEB53 (PT) e ESEB57 (PSDB)

Questão: Agora gostaria de saber com mais detalhes o que o(a) sr(a) pensa sobre alguns partidos políticos. Por favor, use uma nota de 0 a 10 para indicar o quanto o(a) sr(a) gosta do partido que eu vou mencionar. Zero significa que o(a) sr(a) não gosta do partido e dez que o(a) sr(a) gosta muito. Quando eu falar o nome de um partido que o(a) $\operatorname{sr}(a)$ não conhece, apenas diga que não o conhece.

Codificação: 0 (Não gosta), 1, 2, 3, 4, 5, 6, 7, 8, 9, 10 (Gosta muito)

Recodificação: sem recodificação

\section{2) "Pensa PT" e "Pensa PSDB"}

Identificação na Base de Dados: ESEB8

Questão: Qual o partido melhor representa a maneira como o(a) $\operatorname{sr}($ a) pensa?

Codificação: lista com 28 partidos brasileiros, na qual o PT tinha valor 4, e o PSDB tinha valor 8. Recodificação: os partidos analisados foram recodificados como 1 e os outros partidos como 0 na construção de duas variáveis. Respostas como "não sabe", "não respondeu" foram recodificadas como ausentes.

\section{3) Votaria em mulheres para cargos majoritários} (...)?

Identificação na Base de Dados: ESEB64

Questão: Votaria em uma mulher para algum cargo majoritário, como presidente, governadora ou senadora?

Codificação: 1 (Sim) e 2 (Não).

Recodificação: Para a utilização desta variável recodificamos as respostas em 0 (Não) e 1 (Sim).

\section{4) Variáveis de gênero.}

A) Identificação na Base de Dados: ESEB80a

Questão: Agora eu vou ler uma série de frases e gostaria que o(a) $\mathrm{sr}(\mathrm{a})$ me dissesse se discorda muito, discorda, concorda ou concorda muito com cada uma delas.

Em geral homens são mais adequados para a carreira política do que as mulheres.

Codificação: (1) Discorda muito; (2) Discorda; (3) Concorda; (4) Concorda muito; (5) Não concorda nem discorda.

Recodificação: sem recodificação.

B) Identificação na Base de Dados: ESEB80b

Questão: Agora eu vou ler uma série de frases e gostaria que o(a) sr(a) me dissesse se discorda muito, discorda, concorda ou concorda muito com cada uma delas.

Em geral, quando eleitos, homens governam melhor do que mulheres.

Codificação: (1) Discorda muito; (2) Discorda; (3) Concorda; (4) Concorda muito; (5) Não concorda nem discorda.

Recodificação: sem recodificação.

C) Identificação na Base de Dados: ESEB80c

Questão: Agora eu vou ler uma série de frases e gostaria que o(a) sr(a) me dissesse se discorda muito, discorda, concorda ou concorda muito com cada uma delas.

As mulheres ainda não tem experiência política suficiente para governar bem.

Codificação: (1) Discorda muito; (2) Discorda; (3) Concorda; (4) Concorda muito; (5) Não concorda nem discorda.

Recodificação: sem recodificação. 